\title{
A SPECIAL PURPOSE SLIDE RULE FOR COMPUTING SOLID ANGLES
}

\author{
AUTHOR:
}

J. R. Knight

-AK RIDGE gaseous diffusion PLANT Operated by

\section{UNION CARBIDE NUCLEAR COMPANY} DIVISION OF UNION CARBIDE CORPORATION

$$
\text { for the Atomic Energy Commission }
$$

Acting Under U. S. Government Contract W7405 eng 26 
Printed in USA. Price 50 cents. Available from the

Office of Technical Services

U. S. Department of Commerce

Washington $25, \mathrm{D} . \mathrm{C}$.

\section{LEGAL NOTICE}

This report was prepared as an account of Government sponsored work. Neither the United States, nor the Commission, nor any person eeting on behalf of the Commission:

A. Makes any warranty or representation, express or implied, with respect to the accuracy, eompleteness, or usefulness of the information contained in this report, or that the use of any information, apparatus, method, or process disclosed in this report may not infringe privately owned rights; or

B. Assumes any liabilities with respect to the use of, or for damages resulting from the use of any information, apparatus, method, or process disclosed in this report.

As used in the above, "person acting on behalf of the Commission" Includes any employee or contractor of the Commission to the extent that such employee or contractor prepares, handles or distributes, or provides access to, any information pursuant to his employment or contract with the Commission. 
Report Number: $\mathrm{K}-1345$

Subject Category: PHYSICS AND

MATHEMATICS

(TID-4500, 13th Edition)

\section{A SPECIAL PURPOSE SLIDE RULE FOR COMPUTING SOLID ANGLES}

J. R. Knight

Safety, Fire, and Radiation Control Department

Work Supervised By:

H. F. Henry, Ph.D.

K. W。 Bahler, Assistant Plant Superintendent

W. L. Richardson, Assistant Superintendent

Industrial Relations Division

OAK RIDGE GASEOUS DIFFUSION PLANT

A. P. Huber, Plant Superintendent

Union Carbide Nuclear Company

Division of Union Carbide Corporation

Oak Ridge Gaseous Diffusion Plant

Oak Ridge, Tennessee 
Report Number: $\mathrm{K}-1345$

Title: A SPECIAL PURPOSE SLIDE RULE FOR COMPUTING SOLID ANGLES

Author: J. R. Knight

\section{A B S I R A C T}

The design and construction of a slide rule for calculating the solid angle subtended by a rectangle at a point located on a line perpendicular to the center of the rectangle are described. The application of the solid angle to the evaluation of safe spacing between individually subcritical containers of fissionable material is discussed, and a complete derivation of the solidangle equation and a table of values used in marking the slide rule scales are given. 


\section{A SPECIAL PURPOSE SLIDE RULE FOR COMPUTING SOLID ANGLES}

\section{INTRODUCTION}

The evaluation of the solid angle subtended by an object at a given distance from a point is often necessary in various types of problems. of particular interest at the Oak Ridge Gaseous Diffusion Plant is the solid angle between separate units which contain fissionable material, since this is used as the basic criterion for determining the safe spacing of these unitsol Although the calculation of solid angles is in general straightforward, it is frequently laborious, and it is thus desirable to find methods of reducing the time and labor involved in making a fairly large number of such determinations. In order to fulfili this need, a special purpose slide fule for calculating the solid angle subtended by a rectangular object at a point on a line perpendicular to its center has been developed. The slide rule described here yields values from a maximum of $2 \pi$ steradians, which is the largest obtainable between a point and a rectangle, to a minimum of 0.005 steradian, which is the smailest solid angle that is considered to be significant in neutron interaction problems at the Oak Ridge Gaseous Diffusion Plant。

\section{THEORY}

A reasonably rigorous treatment of neutron interaction ${ }^{2}$ shows that the critical spacing between identical and individually subcritical containers of fissionable material is a function of the average solid angle subtended by other containers at the most centrally located one, this average being taken over all points on the surface of the central container. Burton ${ }^{3}$ at the Oak Ridge Gaseous Diffusion Plant, and Pond 4 of the Goodyear Atomic Corporation have developed values of the average solid angle between identical pairs of slabs and cylinders, respectively, and curves giving values of these average solid angles have also been included as an appendix to a more widely distributed report. 2

Despite the fact that a more accurate evaluation of neutron interaction can probably be obtained from consicleration of the average solid angle, the simple solid angle subtended by other containers at a central point of the most centrally located container is useful for nuclear safety evaluations. Not only is this value easily computed, but as will be discussed later in this report, the solid angle so determined is the largest that will be calculated for the given conditions. Thus, to meet a definite solid angle criterion, the spacing specified by this method will be greater, and therefore more conservative, than would be obtained by more rigorous caiculations

1 Henry, $H_{\circ} F_{0}$, Mallett, $A_{\circ} J_{0}$, and Newlon, C。E。, Basic Critical Mass Information and Its Application to Dak Ridge Gaseous Diffusion Plant Design and Operation, August 2, 1957, (K-1019, Fourth Revision), Oak Ridge Gaseous Diffusion Plant, Oak Ridge, Tennessee

2 Henry, $H_{\circ} F_{\circ}$, Knight, $J \circ R \circ$, and Newlon, C. E。, General Application of a Theory of Neutron Interaction, November 15, 1956, (K-1309) Oak Ridge Gaseous Diffusion Plant, Oak Ridge, Tennessee

3 Burton, D。Wo, Average Solid Angles, Letter to H。F. Henry, April 30, 1956, Oak Ridge Gaseous Diffusion Plant, Oak Ridge, Tennessee

4 Pond, Jo A., Right Circular Cylinders, Solid Angle Calculations, June 5, 1956, (GAT-DM 455) Goodyear Atomic Corporation, Portsmouth, Ohio 
Murray and Schmidt 5 have given an expression for the solid angle subtended by a rectangle at a point on a iine perpendicular to one corner. Obviously, this expression may readily be adapted to the problem of the solid angle subtended at a point on a line perpendicular to the center of the rectangle. A chart given in their report enables this type of calculation to be made rather rapidly, but does not yield as great an accuracy as was considered desirable for actual interaction calculations. In addition, it was found that the expression could be put in a somewhat more convenient form than that given by Murray and Schmidt. As a matter of completeness, the entire derivation of their solid angle formula is given in appendix 1 , as is the expression used for developing the slide rule. This is as follows:

$$
\Omega=4 \sin ^{-1} \frac{(a / 2)(b / 2)}{\sqrt{(a / 2)^{2}+h^{2}} \sqrt{(b / 2)^{2}+h^{2}}},
$$

where $a$ and $b$ are the dimensions of the rectangle, and $h$ is the distance of the point from its center. Rearranging the terms and expressing the product as the sum of the logarithms of the terms involved leads to:

$$
\log \csc \Omega / 4=\log \sqrt{1+\left(\frac{2 h}{a}\right)^{2}}+\log \sqrt{1+\left(\frac{2 h}{b}\right)^{2}}
$$

Using this formula, the logarithmic values may be added on the scales of a slide rule to obtain the desired answer. Three scales, one proportional to the $\log \sqrt{1+\left(\frac{2 h}{a}\right)^{2}}$, one proportional to the $\log \sqrt{1+\left(\frac{2 h}{b}\right)^{2}}$ (which is Identical to the previous scale), and one proportional to the $\log \csc \Omega / 4$ are required.

\section{CONSTRUCTION OF THE SLIDE RULE}

Tables of the logarithms of $\sqrt{1+\left(\frac{2 h}{a}\right)^{2}}$ and of $\csc \Omega / 4$, listed in appendix 2, were prepared for appropriate values to be used in marking the scales. These values were plotted to a convenient scale and the total length of the scales was adjusted in the photographic step of the printing process to the slide rule size to be used. In practice, it was found desirable to use 2 ranges for the $\mathrm{h} / \mathrm{b}$ and $\Omega$ scales to obtain the desired range of values. A diagram of a "homemade" slide rule, including regular $C$ and D scales for obtaining the necessary $\mathrm{h} / \mathrm{a}$ and $\mathrm{h} / \mathrm{b}$ ratios, is shown in figure 1 . This slide rule was constructed of transparent plastic to which the scales, printed on heavy paper, were glued. Other types of slide rule construction, such as the circular design, may also be adapted to this type of application.

5 Murray, R. L., and Schmidt, G. W., Methods of Determining Solid Angles, November 25, 1946, Declassified Jan. 18, 1956 (AECD-4056) Tennessee Eastman Corporation, Oak Ridge, Tennessee 


\section{APPLICATION TO NEUTRON INTERACTION PROBLEMS}

It should be noted that the solid angle subtended by a rectangle at a point on a line perpendicular to its center is the largest solid angle that can be obtained for that rectangle at the given distance, both as compared to any point-to-plane determination, and as compared with any average plane-toplane calculation. Accordingly, a calculation between planes using the point-to-plane technique described above will give conservative results. That is, the spacing will be greater than that obtained from what is probably the more accurate method involving the average solid angle. Such a method of calculation should also be adequate to take care of any possible nonconservatism that could result from the fact that the neutron flux density in a reactor is not uniform.

For cylinders, a similar comparison of the results obtained by using a simple point-to-rectangle relation with those obtained from the more detailed average solid angle calculations shows that the simple calculations will also yield a somewhat conservative value of the solid angle if the distance used is from the edge of one cylinder to the center of the other, and the dimensions of the equivalent rectangles are the length and diameter of the cylinders. Presumably, a similar conclusion applies to interaction between other geometrical forms, such as spheres, although this type of calculation has not been attempted. Thus, the slide rule discussed here has a wide general usefulness in safe spacing problems. 
SOLID-ANGLE SLIDE RULE

Developed by the Oak. Ridge Gaseous Diffusion Plant, Oak Ridge, Tennessee

UCe Union Carbide Nuclear Company uce

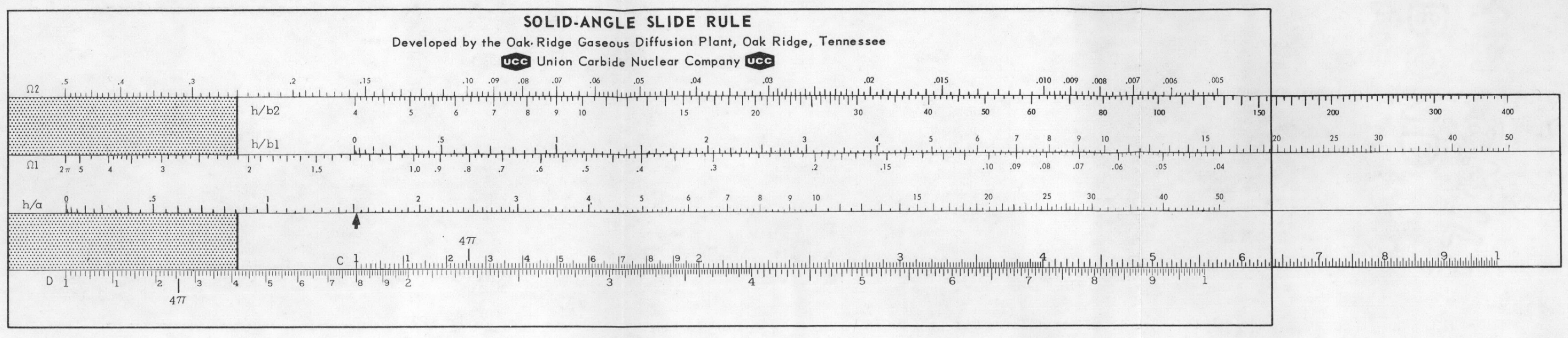

FRONT

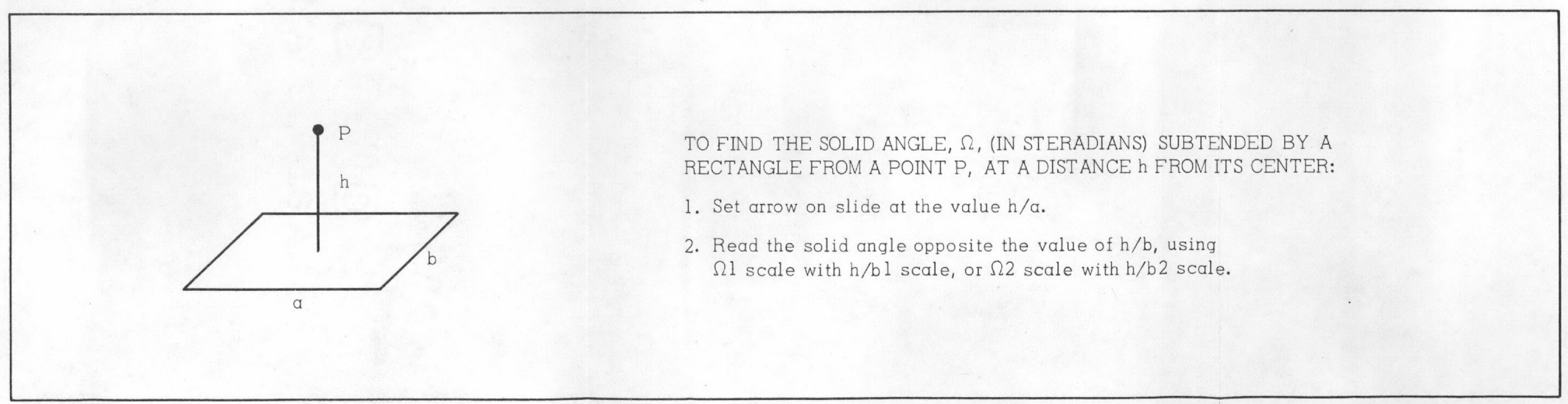

BACK

NOTE: Scale markings as shown are only approximate. 


\section{APPENDIX 1}

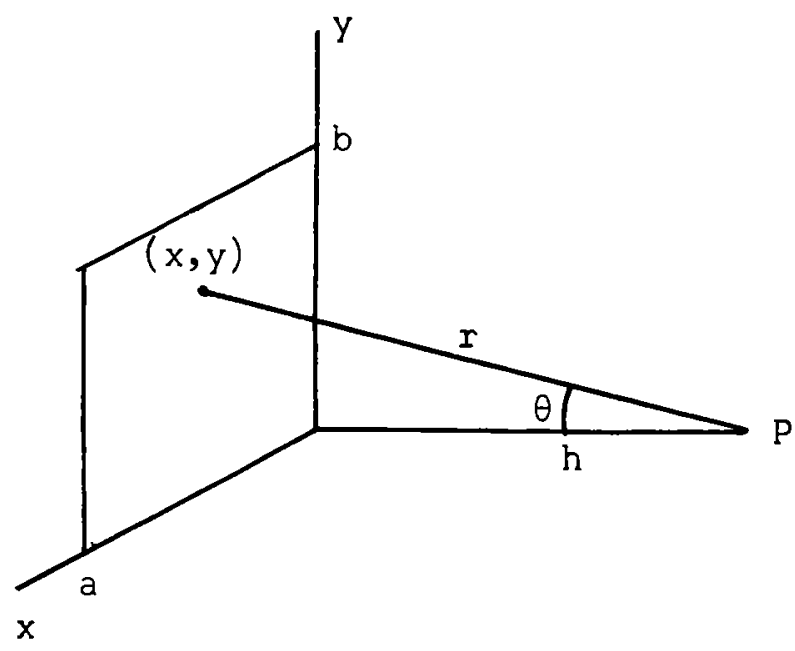

Consider a rectangle, dimensions $a$ and $b$, with a point $P$ at a distance $h$ from one corner. The solid angle $d \Omega$ due to an element of area $d x d y$ at $(x, y)$ is:

$$
\begin{gathered}
d \Omega=\frac{d x d y \cos \theta}{r^{2}} . \\
\cos \theta=\frac{h}{r} ; r=\sqrt{x^{2}+y^{2}+h^{2}} . \\
\therefore d \Omega=\frac{d x d y h}{\sqrt{\left(x^{2}+y^{2}+h^{2}\right)^{3}}} .
\end{gathered}
$$

Thus, the total solid angle due to the rectangle is:

$$
\Omega=\int_{0}^{a} d x \int_{0}^{b} d y \frac{h}{\sqrt{\left(x^{2}+y^{2}+h^{2}\right)^{3}}}
$$

This gives, for the value of $\Omega^{*}$

$$
\begin{aligned}
\Omega & =h \int_{0}^{a} d x\left[\frac{y}{\left(x^{2}+h^{2}\right) \sqrt{x^{2}+y^{2}+h^{2}}}\right]_{0}^{b} \\
& =h b \int_{0}^{a} \frac{d x}{\left(x^{2}+h^{2}\right) \sqrt{x^{2}+h^{2}+b^{2}}} .
\end{aligned}
$$

* Equation No. 122, Handbook of Chemistry and Physics, 32nd Edition, Chemical Rubber Publishing Co., Cleveland, Ohio 
$-8-$

Equation (4) is simplified by the substitution:

$$
u=x^{2}+h^{2}
$$

which gives for $\Omega$ :

$$
\begin{aligned}
\Omega & =\frac{h b}{2} \int_{h^{2}}^{h^{2}+a^{2}} \frac{d u}{u \sqrt{u-h^{2}} \sqrt{u+b^{2}}} \\
& =\frac{h b}{2} \int_{h^{2}}^{h^{2}+a^{2}} \frac{d u}{u \sqrt{u^{2}+\left(b^{2}-h^{2}\right) u-h^{2} b^{2}}}
\end{aligned}
$$

This integral can be expressed in the form:

$$
\Omega=\frac{h b}{2} \int_{h^{2}}^{h^{2}+a^{2}} \frac{d u}{u \sqrt{A+B u+C u^{2}}} .
$$

Integrating this equation yields: ${ }^{*}$

$$
\begin{aligned}
& \Omega=\frac{h b}{2}\left[\frac{1}{\sqrt{h^{2} b^{2}}} \sin ^{-1}\left(\frac{u\left(b^{2}-h^{2}\right)-2 h^{2} b^{2}}{u \sqrt{\left(b^{2}-h^{2}\right)^{2}+4 h^{2} b^{2}}}\right)\right] h^{2}+a^{2} \\
& \therefore \Omega=\frac{1}{2} \sin ^{-1}\left[\frac{\left(h^{2}+a^{2}\right)\left(b^{2}-h^{2}\right)-2 h^{2} b^{2}}{\left(h^{2}+a^{2}\right)\left(b^{2}+h^{2}\right)}\right] \\
& -\frac{1}{2} \sin ^{-1}\left[\frac{h^{2}\left(b^{2}-h^{2}\right)-2 h^{2} b^{2}}{h^{2}\left(b^{2}+h^{2}\right)}\right] \cdot \\
& \Omega=\frac{1}{2} \sin ^{-1}\left[\frac{a^{2} b^{2}-h^{2}\left(a^{2}+b^{2}\right)-h^{4}}{\left(h^{2}+a^{2}\right)\left(h^{2}+b^{2}\right)}\right]+\frac{1}{2} \sin ^{-1} 1 . \\
& \Omega=\frac{1}{2} \sin ^{-1}\left[\frac{a^{2} b^{2}-h^{2}\left(a^{2}+b^{2}\right)-h^{4}}{\left(h^{2}+a^{2}\right)\left(h^{2}+b^{2}\right)}\right]+\frac{\pi}{4} .
\end{aligned}
$$

Equation No. 167, Handbook of Chemistry and Physics, 32nd Edition Chemical Rubber Publishing Co., Cleveland, Ohio 
This expression is equivalent to one of the expressions given by Murray and Schmidt.5 However, by means of a few substitutions, equation (9) can be put in a more convenient form.

$$
\begin{aligned}
& 2 \Omega-\frac{\pi}{2}=\sin ^{-1}\left[\frac{2 a^{2} b^{2}-\left\{h^{4}+h^{2}\left(a^{2}+b^{2}\right)+a^{2} b^{2}\right\}}{\left(h^{2}+a^{2}\right)\left(h^{2}+b^{2}\right)}\right] ; \\
& \sin \left\{2 \Omega-\frac{\pi}{2}\right\}=\frac{2 a^{2} b^{2}}{\left(h^{2}+a^{2}\right)\left(h^{2}+b^{2}\right)}-1 \\
& =\sin 2 \Omega \cos \frac{\pi}{2}-\cos 2 \Omega \sin \frac{\pi}{2} \cdot \\
& \therefore \cos 2 \Omega=1-\frac{2 a^{2} b^{2}}{\left(h^{2}+a^{2}\right)\left(h^{2}+b^{2}\right)}=1-2 \sin ^{2} \Omega \\
& \therefore \quad \sin ^{2} \Omega=\frac{a^{2} b^{2}}{\left(h^{2}+a^{2}\right)\left(h^{2}+b^{2}\right)} ; \\
& \Omega=\sin { }^{-1} \frac{a b}{\sqrt{\left(h^{2}+a^{2}\right)\left(h^{2}+b^{2}\right)}} \\
& \therefore
\end{aligned}
$$

Equation (14) has the advantages of compactness and simplicity of calculation. For a point $P$ at a distance $h$ from the center of a rectangle, we have:

$$
\begin{aligned}
& \Omega=4 \sin ^{-1} \frac{(a / 2)(b / 2)}{\sqrt{(a / 2)^{2}+h^{2}} \sqrt{(b / 2)^{2}+h^{2}}} \sin \Omega / 4= \\
&=\frac{(a / 2)(b / 2)}{\sqrt{(a / 2)^{2}+h^{2}} \sqrt{(b / 2)^{2}+h^{2}}} \\
& \operatorname{csc~} \Omega / 4=\sqrt{1+\left(\frac{2 h}{a}\right)^{2}} \sqrt{1+\left(\frac{2 h}{b}\right)^{2}}
\end{aligned}
$$

Equation (16) gives the cosecant of $\Omega / 4$ in terms of the product of 2 terms whose values depend on the ratio of $h / a$ and $h / b$; thus the solid angle may 
be computed on a slide rule by adding logarithmic scales, as follows:

$$
\log \csc \Omega / 4=\log \sqrt{1+\left(\frac{2 h}{a}\right)^{2}}+\log \sqrt{1+\left(\frac{2 h}{b}\right)^{2}}
$$




\section{APPENDIX 2}

SCALE MARKINGS FOR THE SLIDE RULE

The following tables list the marks and scale position for the solid angle slide rule scales. The marks comprising the scales were of 3 lengths, the length of each mark being indicated in the tables by asterisks as follows:

1. Shortest marks - no symbol.

2. Medium marks* ${ }^{*}$

3. Longest marks ${ }^{* *}$.

4. Longest marks, with numerals ${ }^{* *}$. 
SCALE MARKINGS FOR $\Omega$ SCALES

\begin{tabular}{|c|c|c|c|}
\hline$\Omega$ & $\log \operatorname{Csc} \Omega / 4$ & $\Omega$ & $\log \operatorname{Csc} \Omega / 4$ \\
\hline $2 \pi^{* * *}$ & 0 & .88 & .6611 \\
\hline $5 * * *$ & .0243 & .86 & .6709 \\
\hline 4.5 & .0447 & .84 & .6810 \\
\hline $4^{* * *}$ & .0750 & .82 & .6913 \\
\hline 3.9 & .0821 & $.8^{* * *}$ & .7019 \\
\hline 3.8 & .0897 & & \\
\hline 3.7 & .0977 & .78 & .7127 \\
\hline 3.6 & .1060 & .76 & .7239 \\
\hline $3.5^{* *}$ & .1149 & .74 & .7353 \\
\hline 3.4 & .1242 & .72 & .7471 \\
\hline 3.3 & .1340 & $.7^{* * *}$ & .7592 \\
\hline 3.2 & .1443 & & \\
\hline 3.1 & .1551 & .68 & .7716 \\
\hline & & .66 & .7845 \\
\hline $3^{* * *}$ & 1665 & .64 & .7977 \\
\hline 2.9 & .1784 & .62 & .8114 \\
\hline 2.8 & .1910 & $.6^{* * *}$ & .8255 \\
\hline 2.7 & .2042 & & \\
\hline 2.6 & .2181 & .59 & .8328 \\
\hline $2.5^{* *}$ & .2328 & .58 & .8402 \\
\hline 2.4 & .2482 & .57 & .8477 \\
\hline 2.3 & .2645 & .56 & .8553 \\
\hline 2.2 & .2817 & $.55^{* *}$ & .8631 \\
\hline 2.1 & .3000 & .54 & .8710 \\
\hline \multirow[t]{2}{*}{$2^{* * *}$} & .3193 & .53 & .8791 \\
\hline & & .52 & .8873 \\
\hline 1.95 & .3294 & .51 & . 8957 \\
\hline $1.9^{*}$ & .3396 & & \\
\hline 1.85 & .3505 & $.5^{* * *}$ & .9042 \\
\hline $1.8^{*}$ & .3615 & .49 & .9129 \\
\hline 1.75 & .3730 & .48 & .9219 \\
\hline $1.7^{*}$ & .3848 & .47 & .9310 \\
\hline 1.65 & .3969 & .46 & .9403 \\
\hline $1.6^{*}$ & .4096 & $.45^{* *}$ & .9498 \\
\hline \multirow[t]{2}{*}{1.55} & .4226 & .44 & .9595 \\
\hline & & .43 & .9694 \\
\hline $1.5^{* * *}$ & .4362 & .42 & .9796 \\
\hline 1.45 & .4502 & .41 & .9900 \\
\hline $1.4^{*}$ & .4648 & & \\
\hline 1.35 & .4800 & $.4^{* * *}$ & 1.0008 \\
\hline $1.3^{*}$ & .4958 & .39 & 1.0117 \\
\hline 1.25 & .5122 & .38 & 1.0229 \\
\hline $1.2^{*}$ & .5294 & .37 & 1.0345 \\
\hline 1.15 & .5474 & .36 & 1.0458 \\
\hline $1.10^{*}$ & .5662 & $.35^{* *}$ & 1.0585 \\
\hline \multirow[t]{2}{*}{1.05} & .5859 & .34 & 1.0711 \\
\hline & & .33 & 1.0840 \\
\hline $1.0^{* * *}$ & .6066 & .32 & $§ .0973$ \\
\hline .98 & .6152 & .31 & 1.1110 \\
\hline .96 & .6239 & & \\
\hline .94 & .6329 & & \\
\hline .92 & .6421 & & \\
\hline $.9^{* * *}$ & .6515 & & \\
\hline
\end{tabular}

$\begin{array}{ll}\frac{\Omega}{.3 * *}^{* *} & \frac{\log \operatorname{Csc} \Omega / 4}{1.1256} \\ .29 & 1.1400 \\ .28 & 1.1552 \\ .27 & 1.1709 \\ .26 & 1.1874 \\ .25^{* *} & 1.2044 \\ .24 & 1.2221 \\ .23 & 1.2406 \\ .22 & 1.2581 \\ .21 & 1.2800\end{array}$

$\begin{array}{ll}.2^{* * *} & 1.3012 \\ .195 & 1.3122 \\ .190^{*} & 1.3235 \\ .185 & 1.3350 \\ .180^{*} & 1.3469\end{array}$

$.180^{*} \quad 1.3469$

$.175 \quad 1.3591$

$.170^{*} \quad 1.3717$

$.165 \quad 1.3847$

$.160^{*} \quad 1.3980$

$.155 \quad 1.4118$

$.15^{* * *} \quad 1.4261$

$.145 * \quad 1.4408$

$.140^{*} \quad 1.4560$

$.135 \quad 1.4718$

$.130^{*} \quad 1.4882$

$.125 \quad 1.5052$

$.120^{*} \quad 1.5229$

$.115 \quad 1.5414$

$.110^{*} \quad 1.5607$

$.105 \quad 1.5809$

$.10^{* * *} \quad 1.6021$

$.098 \quad 1.6109$

$.096 \quad 1.6198$

$.094 \quad 1.6290$

.0921 .6383

$.09^{* *} \quad 1.6479$

$.088 \quad 1.6576$

$.086 \quad 1.6676$

$.084 \quad 1.6778$

$.082 \quad 1.6883$

$.08^{* * *} \quad 1.6990$

$.078 \quad 1.7100$

$.076 \quad 1.7213$

$.074 \quad 1.7329$

$.072 \quad 1.7447$ 


\begin{tabular}{|c|c|c|c|c|c|}
\hline$\Omega$ & $\log \operatorname{Csc} \Omega / 4$ & $\Omega$ & $\log \operatorname{Csc} \Omega / 4$ & $\Omega$ & $\log \operatorname{Csc} \Omega / 4$ \\
\hline $.07^{* * *}$ & 1.7570 & $.025^{* *}$ & 2.2041 & $.007^{* * *}$ & 2.7570 \\
\hline .068 & 1.7696 & .0245 & 2.2128 & .0068 & 2.7695 \\
\hline .066 & 1.7825 & $.024^{*}$ & 2.2218 & .0066 & 2.7825 \\
\hline .064 & 1.7959 & .0235 & 2.2310 & .0064 & 2.7959 \\
\hline .062 & 1.8097 & $.023^{*}$ & 2.2403 & .0062 & 2.8097 \\
\hline $.06^{* * *}$ & 1.8239 & .0225 & $\begin{array}{l}2.2498 \\
2.2596\end{array}$ & $.006^{* * *}$ & 2.8239 \\
\hline .059 & 1.8312 & .0215 & 2.2696 & .0059 & 2.8312 \\
\hline .058 & 1.8386 & $.021^{*}$ & 2.2798 & .0058 & 2.8386 \\
\hline .057 & 1.8462 & .0205 & 2.2903 & .0057 & 2.8462 \\
\hline .056 & 1.8539 & & & .0056 & 2.8539 \\
\hline $.055^{* *}$ & 1.8617 & $.02^{* * *}$ & 2.3010 & $.0055^{* *}$ & 2.8617 \\
\hline .054 & 1.8697 & .0195 & 2.3120 & .0054 & 2.8697 \\
\hline .053 & 1.8778 & $.019^{*}$ & 2.3233 & .0053 & 2.8778 \\
\hline .052 & 1.8861 & .0185 & 2.3349 & .0052 & 2.8860 \\
\hline .051 & 1.8945 & $.018^{*}$ & 2.3468 & .0051 & 2.8945 \\
\hline & & .0175 & 2.3590 & & \\
\hline $.05^{* * *}$ & 1.9031 & $.017^{*}$ & 2.3716 & $.005^{* * *}$ & 2.9031 \\
\hline .049 & 1.9119 & .0165 & 2.3846 & & \\
\hline .048 & 1.9208 & $.016^{*}$ & 2.3979 & & \\
\hline .047 & 1.9300 & .0155 & 2.4117 & & \\
\hline .046 & 1.9393 & & & & \\
\hline $.045^{* *}$ & 1.9488 & $.015^{* * *}$ & 2.4259 & & \\
\hline .044 & 1.9586 & .0145 & 2.4407 & & \\
\hline .043 & 1.9686 & $.014^{*}$ & 2.4559 & & \\
\hline .042 & 1.9788 & .0135 & 2.4717 & & \\
\hline .041 & 1.9893 & $.013^{*}$ & 2.4881 & & \\
\hline & & .0125 & 2.5052 & & \\
\hline $.04^{* * *}$ & 2.0000 & $.012^{*}$ & 2.5229 & & \\
\hline .039 & 2.0110 & .0115 & 2.5414 & & \\
\hline .038 & 2.0223 & $.011^{*}$ & 2.5606 & & \\
\hline .037 & 2.0338 & .0105 & 2.5809 & & \\
\hline .036 & 2.0454 & & & & \\
\hline $.035^{* *}$ & 2.0580 & $.010^{* * * *}$ & 2.6021 & & \\
\hline .034 & 2.0706 & .0098 & 2.6108 & & \\
\hline .033 & 2.0836 & .0096 & 2.6198 & & \\
\hline .032 & 2.0969 & .0094 & 2.6289 & & \\
\hline .031 & 2.1107 & .0092 & 2.6383 & & \\
\hline $.03^{* * *}$ & 2.1249 & $.009^{* * *}$ & 2.6478 & & \\
\hline .0295 & 2.1322 & .0088 & 2.6576 & & \\
\hline $.029^{*}$ & 2.1397 & .0086 & 2.6676 & & \\
\hline .0285 & 2.1472 & .0084 & 2.6778 & & \\
\hline $.028^{*}$ & 2.1549 & .0082 & 2.6882 & & \\
\hline .0275 & 2.1627 & & & & \\
\hline $.027^{*}$ & 2.1707 & $.008^{* * *}$ & 2.6990 & & \\
\hline .0265 & 2.1788 & .0078 & 2.7100 & & \\
\hline $.026^{*}$ & 2.1871 & .0076 & 2.7212 & & \\
\hline .0255 & 2.1955 & .0074 & 2.7328 & & \\
\hline & & .0072 & 2.7447 & & \\
\hline
\end{tabular}


SCALE MARKINGS FOR $\mathrm{h} / \mathrm{a}$ AND $\mathrm{h} / \mathrm{b}$ SCALES

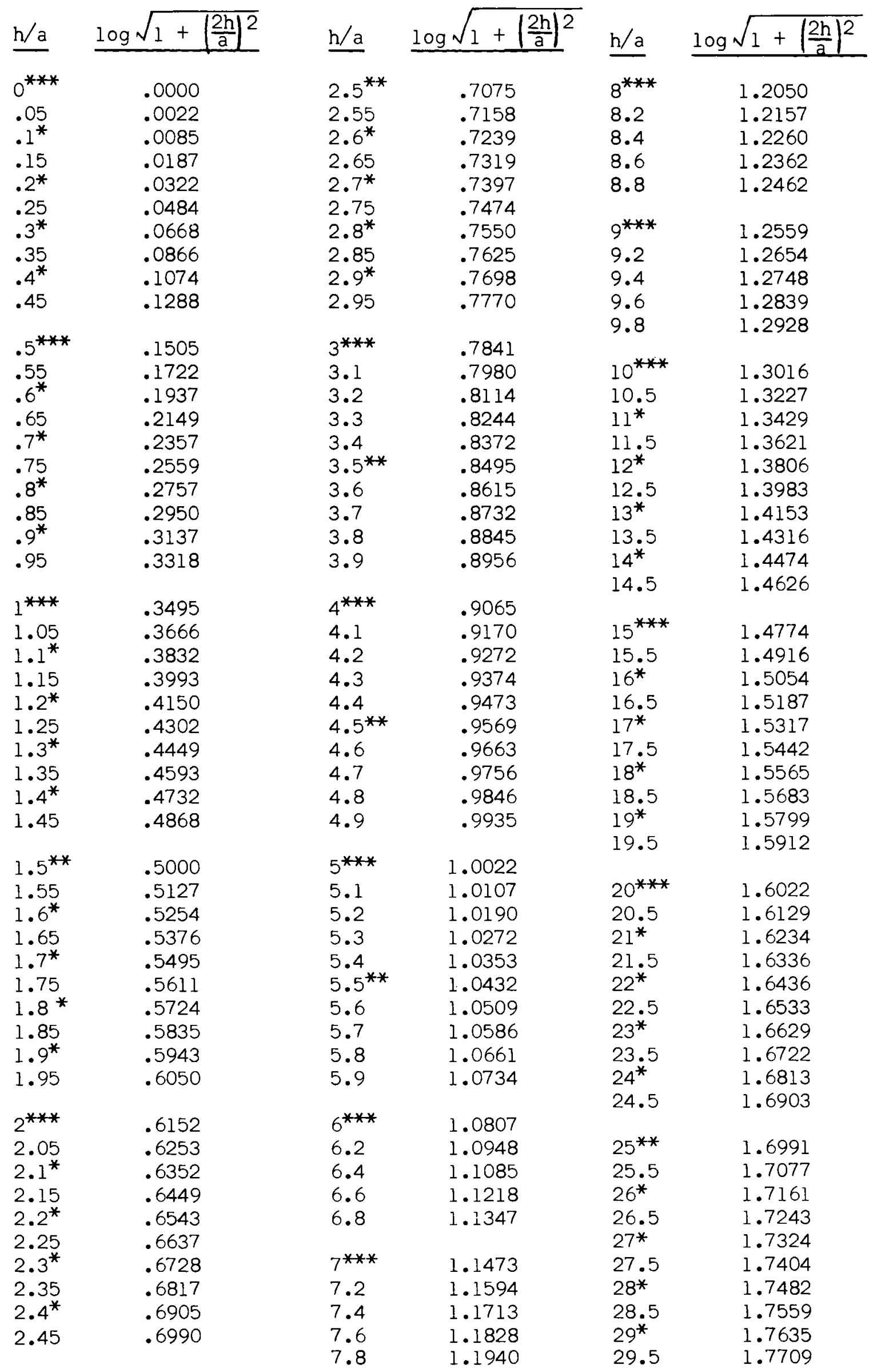




\section{$\underline{h / a} \quad \underline{\log \sqrt{1+\left(\frac{2 h}{a}\right)^{2}}}$}

$\begin{array}{ll}30^{* * *} & 1.7782 \\ 31 & 1.7924 \\ 32 & 1.8062 \\ 33 & 1.8196 \\ 34 & 1.8325 \\ 35^{* *} & 1.8451 \\ 36 & 1.8574 \\ 37 & 1.8693 \\ 38 & 1.8808 \\ 39 & 1.8921\end{array}$

$\begin{array}{ll}40^{* * *} & 1.9031 \\ 41 & 1.9138 \\ 42 & 1.9243 \\ 43 & 1.9345 \\ 44 & 1.9445 \\ 45^{* *} & 1.9543 \\ 46 & 1.9638 \\ 47 & 1.9731 \\ 48 & 1.9823 \\ 49 & 1.9912\end{array}$

$\begin{array}{ll}50^{* * *} & 2.0000 \\ 52 & 2.0170 \\ 54 & 2.0334 \\ 56 & 2.0492 \\ 58 & 2.0645\end{array}$

$\begin{array}{ll}60^{* * *} & 2.0792 \\ 62 & 2.0934 \\ 64 & 2.1072 \\ 66 & 2.1206 \\ 68 & 2.1335 \\ 70^{* * *} & 2.1461 \\ 72 & 2.1584 \\ 74 & 2.1703 \\ 76 & 2.1818 \\ 78 & 2.1931\end{array}$

$\begin{array}{ll}80^{* * *} & 2.2041 \\ 82 & 2.2148 \\ 84 & 2.2253 \\ 86 & 2.2355 \\ 88 & 2.2455\end{array}$

$\begin{array}{ll}90^{* * *} & 2.2553 \\ 92 & 2.2648 \\ 94 & 2.2742 \\ 96 & 2.2833 \\ 98 & 2.2923\end{array}$

$\underline{\mathrm{h} / \mathrm{a}} \quad \underline{\log \sqrt{1+\left(\frac{2 h}{2}\right)^{2}}}$

$100^{* * *} \quad 2.3010$

$105 \quad 2.3222$

$110^{*}$

115

$120^{*}$

125

$130^{*}$

135

$140^{*}$

145

$150^{* * *}$

155

$160^{*}$

165

$170^{*}$

175

$180^{*}$

185

$190^{*}$

195

2.3424

2.3617

2.3802

2.3979

2.4150

2.4314

2.4472

2.4624

2.4771

2.4914

2.5052

2.5185

2.5315

2.5441

2.5563

2.5682

2.5798

2.5911

$\begin{array}{ll}200^{* *} & 2.6021 \\ 205 & 2.6128 \\ 210^{*} & 2.6232 \\ 215 & 2.6335 \\ 220^{*} & 2.6435 \\ 225 & 2.6532 \\ 230^{*} & 2.6628 \\ 235 & 2.6721 \\ 240^{*} & 2.6812 \\ 245 & 2.6902 \\ & \\ 250^{* *} & 2.6990 \\ 255 & 2.7076 \\ 260^{*} & 2.7160 \\ 265 & 2.7243 \\ 270^{*} & 2.7324 \\ 275 & 2.7404 \\ 280^{*} & 2.7482 \\ 285 & 2.7559 \\ 290^{*} & 2.7634 \\ 295 & 2.7709 \\ 300^{* * *} & 2.7782 \\ 310 & 2.7924 \\ 320 & 2.8062 \\ 330 & 2.8195 \\ 340 & 2.8325 \\ 350^{* *} & 2.8451 \\ 360 & 2.8573\end{array}$

$\underline{h / a} \quad \underline{\log \sqrt{1+\left(\frac{2 h}{2}\right)^{2}}}$

$370 \quad 2.8692$

$380 \quad 2.8808$

$390 \quad 2.8921$

$400^{* *} \quad 2.9031$ 

